\title{
PAISAGEM, MEIO AMBIENTE E PLANEJAMENTO
}

\author{
Manoel Carlos de OLIVEIRA*
}

\begin{abstract}
RESUMO
A paisagem tem amplas relações com o meio ambiente. Seu estudo é composto de temas que são de grande importância para o planejamento ambiental. Alguns desses temas, tais como, conceito de paisagem, sua tipologia, são abordados neste trabalho que apresenta ainda uma tentativa de regionalização da paisagem no Estado de São Paulo. Esta regionalização baseia-se na relação existente entre embasamento geológico/geomorfológico e fatores culturais que se expressam no espaço criando unidades.
\end{abstract}

\begin{abstract}
The landscape has broad relationships with environment. Its studying is based on themes which are important for the environmental planning. Some of these themes are presented in this work, with an attempt of the regionalization in São Paulo State. This regionalization is based in the relationship between geological/geomorphological basis and the cultural factor which are expressed in the space creating units.
\end{abstract}

\section{INTRODUÇÃO}

Os anos de 1982-1983 foram excepcionalmente chuvosos no sul do Brasil acarretando catástrofes de grande monta, cidades inteiras foram alagadas. Logo após esse período de grande pluviosidade houve um verão extremamente seco em 1984 que provocou ou perda ou diminuição de safras agrícolas.

$\mathrm{O}$ quadro apresentado acima sugere que se coloque mais uma vez em discussão a questão ambiental, que nos últimos tempos vem sendo eclipsada pela preocupação com a crise econômica.

Os problemas ambientais vão se agravando cada vez mais, aliado aos problemas econômicos que muitas vezes tem a mesma origem. Ao lado do crescimento demográfico descontrolado, tem se a diminuição das safras agrícolas, o custo sempre crescente dos alimentos e a perda gradativa da qualidade de vida. O espaço agrí́cola sofre concorrência do espaço urbano, em decorrência do crescimento desmesurado das cidades nos países subdesenvolvidos que por sua vez é fruto da migração descontrolada. A passividade das pessoas frente a crise é a tônica dominante, as autoridades e técnicos prefe- rem aplicar medidas paliativas, populistas sem enfrentar o cerne da questão. Muitas vezes, devido a uma distorção de ótica e algumas vezes por comodismo é preferível apelar para o populismo, na medida em que este último fato permite desviar a atenção dos problemas reais.

Existem pessoas tentando desencadear uma ação no sentido de reverter o estado em que se encontra a questão ambiental no Brasil. A próprio comunidade se organiza e reivindica uma ação mais objetiva através dos movimentos ambientalistas. Existem técnicos coerentes, mas solitários, tentando apresentar soluções. Os meios de comunicação tem vindo a público com denúncias, que se tornam inócuas, na medida em que não estão gerando nenhuma ação eficaz. Não tem havido nenhuma desaceleração da crise ambiental atual. Ela se agrava a cada dia. O planejamento como uma solução tornouse neste país um termo pejorativo, pois o que se tem feito de planos os quais não dão certo ou prejudicam mais do que ajudam, é indescritível. No entanto é necessário restabelecer a credibilidade no planejamento, principalmente no caso específico do meio ambiente. Sem dúvida são os países onde o

* Instituto Geológico - Caixa Postal 8772 - 01000 - São Paulo, SP, Brasil 
planejamento e a organização são levados a sério que a crise ambiental tem sido contornada satisfatoriamente, vide exemplos do Japão, União Soviética, Estados Unidos. A Alemanha é hoje em dia o paraiso do planejamento ambiental, no que se refere ao manejo das áreas verdes.

Este trabalho é uma tentativa de colocar em discussão a questão ambiental através da paisagem, uma das formas de expressão do meio ambiente e da natureza em sua organização. A natureza em sua organização cria esquemas bastante rígidos. E necessário que o Homem aprenda a interpretá-la para produzir organizações que lhe sejam compatíveis. No dizer de BERNALDEZ (1981) paisagem é informação e portanto, está aí a nos contar como conviver com ela. Procura-se assim colocar em discussão vários temas sobre a paisagem, sua interpretação e a importância destas discussões para 0 planejamento do meio ambiente como um todo.

\section{A PAISAGEM E SEU CONCEITO}

O estudo da paisagem envolve um número muito grande de conceitos e procurase citar os principais e mais abrangentes para compreender sua organização e funcionamento.

Segundo BERTRAND (1972) a paisagem é a confluência entre geografia e ecologia. Era a princípio uma denominação que possuía caráter mais botânico, sendo posteriormente adotada pelos geógrafos que aí concentraram seus estudos. Troll, em 1938, estabeleceu o conceito de geoecologia ou ecologia da paisagem. Ele foi buscar muitos de seus conceitos na ecologia, como por exemplo, o conceito de ecossistema.

$\mathrm{O}$ ecossistema foi um termo criado por Transley em 1935 para caracterizar um sistema aberto composto de biotopo e biocenose. O biotopo corresponde o espaço onde se processa as relações entre os seres vivos, as biocenoses, que estão intimamente associadas a ele em função da existência de recursos alimentares disponíveis. Os ecossistemas são unidades espaciais hierarquizada, em função de balanço energético específico, com suas entradas, fluxos e saídas de energia. Formam-se assi n macro, meso e microecossistemas. Para o estudo da paisagem interessam mais os mesoecossistemas onde aparecem as florestas, os lagos; e os macroecossistemas, com os oceanos, os continentes. São nessas unidades onde ocorrem as relações de espaço mais expressivas para os geógrafos.

SOTCHAVA apud DEMEK (1978) introduziu o termo geossistema para descrever a paisagem como um sistema com todos seus subsistemas componentes. A paisagem como um geossistema é caracterizada pelos seguintes aspectos: DEMEK (1978) "posição na superfície da terra; limites definidos; aspectos externos específicos; estruturas específicas e relações de feedbacks entre subsistemas abióticos, solo, bióticos e sócio econômicos; balanço específico de energia; desenvolvimento acima do espaço e tempo dependendo dos in puts e out puts variáveis de massa e energia no geossistema."

SOTCHAVA (1977) mostra a relação existente entre ecossistema e geossistema. "Ecossistema de biocenose são complexos monocêntricos (biocêntricos) nos quais o ambiente natural e suas bases abióticas são examinadas do ponto de vista de suas conexões com os organismos". "Geossistemas abrangem complexos biológicos e possuem uma organização de sistemas mais complexa." "Geossistemas são policêntricos."

$\mathrm{Na}$ realidade o geossistema funciona como uma unidade espacial mais abrangente podendo englobar um número muito grande de ecossistemas, é o caso da região de Campos do Jordão na Serra da Mantiqueira.

Para complementar o estudo conceitual da paisagem seguem três conceitos que tratará do assunto. BERTRAND (1971) considera a paisagem como "uma determinada porção do espaço, o resultado da combinação dinâmica portanto instável, de elementos físicos, biológicos e antrópicos que reagindo dialeticamente uns sobre os outros, fazem da paisagem um conjunto único e indissociável em perpétua evolução". TROLL apud SEIBERT (1974) fala em aspectos internos e externos da paisagem. A conjugação desses aspectos formam unidades regionais.

OLIVEIRA $(1976,1982)$ define meio ambiente como um determinado espaço constituído de componentes que estão relacionados entre si. Em OLIVEIRA et alii (1976) a paisagem é mostrada como o aspecto visual do meio ambiente. Os componentes da paisagem são igualmente os do meio ambiente abióticos, bióticos, solo e componente cultural. Representam o arranjo externo.

Nesses conceitos verifica-se que a paisagem representa espaço e arranjos de com 
ponentes que se expressam visualmente. Ela tem um funcionamento que decorre de um dinamismo (aspecto interno) que é o estado de relação entre componentes que reagem entre si. São mutáveis mas dentro de um equilíbrio dinâmico (OLIVEIRA, 1982). Em decorrência a estes fatos a paisagem aparece como uma estrutura quase estática, pois sua mutação é praticamente invisível e a longo prazo. Somente o homem quando entra como componente cultural transforma a paisagem com grande rapidez podendo provocar a perda do equilíbrio natural dinâmico (OLIVEIRA, 1982).

\section{TIPOLOGIA DA PAISAGEM}

Os tipos de paisagem apresentados a seguir baseiam-se em uma classificação que decorre da predominância de alguns fatores no arranjo dos componentes da paisagem. São de interesse para o planejamento, pois mostram o grau de interferência do homem na natureza.

O primeiro tipo que surge é o da paisagem natural, onde predominam o arranjo dos componentes bióticos, abióticos e o solo, muito pouco alterados, sendo que o fator cultural é inexpressivo. Hoje em dia é difícil encontrar uma paisagem eminentemente natural, não tocada pelo homem. A ação deste é planetária, provocando alterações da mesma proporção. A poluição atinge a atmosfera em sua totalidade com diversos graus de concentração de poluentes que atuam por toda parte.

Pode-se dividir a paisagem natural em original e alterada. No primeiro caso os níveis de ação humana são mínimos. O homem pode conviver com as paisagens originais sem causar nenhuma modificação. E o caso dos índios brasileiros que vivem em perfeita comunhão com a natureza. Suas atividades não causam alterações no ambiente, pois são concentradas e itinerantes e não apresentam grande magnitude de ações.

No Estado de São Paulo somente algumas regiões da Serra do Mar, mais inacessíveis podem ser consideradas como paisagens originais. $\mathrm{O}$ Vale do Rio Ribeira de Iguape tinha regiões com estas características. Na atualidade a pressão sócio-econômica e a posse da terra de forma desordenada estão contribuindo para alterar de modo negativo a paisagem, nessa região.

O segundo tipo de paisagem é a natural -alterada. A mata secundária é um tipo de reação ambiental à alteração de uma área, causada pelo homem onde havia primitivamente uma floresta. Pode constituir-se em um ecossistema estável em resposta às novas condições de biotopo.

Em relação à paisagem cultural foram selecionados alguns conceitos que para efeito de planejamento apresentam aspectos bastante ricos de interesse. Aparece no primeiro caso a paisagem cultural quanto ao aspecto predominante da ocupação humana. É vista através de elementos visuais que foram criados através de novos arranjos dos componentes abióticos-bióticos acrescidos dos componentes culturais. Tem-se por exemplo a paisagem urbana, no caso das cidades; a paisagem rural, nas áreas onde predominam as atividades agropecuárias e as paisagens ruro-urbanas, quando a agricultura e cidades se mesclam. Área rural versus urbana criam uma relação dialética, onde uma área procura anular a outra. $\mathrm{Na}$ atualidade o crescimento desenfreado das cidades nos países subdesenvolvidos anulam muitas vezes zonas de solos bastante ricos. São em geral países carentes de alimentos e necessitam explorar cuidadosamente seus recursos agrícolas para garantir a sobrevivência de uma população que cresce de forma desenfreada. No Estado de São Paulo aparece exemplos gritantes deste fato. São as áreas de terra roxa, o solo mais rico do estado, que vem sendo invadidas por cidades como Campinas, Jaú, em decorrência de sua expansão territorial.

Quanto à organização das atividades surgem as paisagens planejadas, e/ou de intervenção aleatória. Quanto às primeiras, algumas são realizadas utilizando-se técnicas primitivas, onde se criam ambientes muito estáveis em função do uso da terra. Isto ocorre nas regiões de agricultura em terraceamentos, na Ásia de Sudeste.

Hoje em dia, as paisagens organizadas com técnicas modernas podem ser estáveis, decorrentes do equilíbrio cultural dinâmico (OLIVEIRA, 1982), ou não. O uso que se vem fazendo dessas áreas é intenso e muitas vezes sem promover a necessária pausa para recuperar suas condições potenciais. Onde se aplica a tecnologia branda, aquelas que alteram o mínimo as condições naturais, pode-se criar relações ambientais bastante estáveis. Nessas áreas pratica-se o controle biológico das pragas e evita-se as substâncias poluentes que envenenam 0 meio ambiente. É o caso das fazendas bio- 
dinâmicas que já existem no Estado de São Paulo.

Muitas das regiões planejadas com tecnologia pesada, principalmente as agrícolas, tornaram-se bastante degradadas, pois essa tecnologia contribui para desagregar o solo e facilitar sua erosão. Os Estados Unidos exportaram modelos tecnológicos baseados em uma mecanização excessiva. Com isto a produtividade agrícola era muito alta. No entanto verificou-se posteriormente que os danos à natureza eram intensos e a recuperação das condições primitivas onerosas e difíceis.

A intervenção aleatória da paisagem se faz tanto com técnicas modernas quanto primitivas. No primeiro caso estão as construções de estradas que são feitas com o mínimo de planejamento, usando maquinarias pesadas. Essas rodovias são construídas sem levar em conta o potencial da paisagem que em decorrência desse fato provoca uma série de catástrofes que muitas vezes destroe essas rodovias. É o caso da Rodovia dos Imigrantes. Quando ela começou a desabar surgiu a preocupação de recuperar, seu entorno que estava bastante degradado.

Nas áreas onde a intervenção aleatória sem ser intensa, é feita com técnicas primitivas, não há alterações significativas na paisagem quando os impactos são mínimos. Com o aumento desses impactos começam a acontecer as catástrofes. O exemplo marcante é o das favelas construídas nas encostas de montanhas, em regiões quentes e úmidas. São áreas de grande instabilidade, sujeitas a escorregamentos que ocorrem nas épocas de maior pluviosidade.

\section{A AÇÃO DO HOMEM E O IMPACTO AMBIENTAL}

O resultado da intervenção aleatória do homem na paisagem, desconsiderando seu potencial, representa o impacto ambiental. Este último implica numa pressão sobre o arranjo estrutural dos componentes do sistema ambiental, alterando seu dinamismo negativamente, criando novos sistemas que nem sempre são favoráveis ao homem. A natureza reage tentando criar novas formas de equilíbrio. A intervenção aleatória pode ocorrer de várias maneiras, seja eliminando a vegetação para implantar atividades agrícolas, ou para promover loteamentos urbanos, seja promovendo obras de terraplanagem que destroem o solo e provocam ampla erosão.

O Homem potencializa uma relação de causa e efeito que se torna bastante ampla, abrangendo todo um arranjo ambiental em determinada unidade de espaço. Pode criar assim novos arranjos que são desfavoráveis à ocupação humana. Os efeitos dessa relação em geral são acumulativos, de difícil previsão e decorre da vulnerabilidade do meio ambiente. Quanto mais vulnerável for esse meio, maior será a duração e extensão do impacto aí existente.

A figura 1 mostra uma sequiência dos impactos exercidos sobre os componentes da paisagem e são classificados em ordem de interferência direta, que são os impactos de efeito imediatos e, de interferência indireta, derivados dos primeiros.

No quadro que acompanha este ítem estão explicados com maiores detalhes a seqüências, suas fontes de origem. 
Rev. IG, São Paulo, 4(1/2): 67-78, jan./dez. 1983

\begin{tabular}{|c|c|c|c|}
\hline \multicolumn{4}{|c|}{ SEQUUENCIA DE IMPACTOS AMBIENTAIS } \\
\hline \multicolumn{4}{|c|}{ Interferência Direta } \\
\hline $\begin{array}{l}\text { Componentes } \\
\text { da paisagem }\end{array}$ & Fontes de Impacto & Impacto & Impacto Derivado \\
\hline Ar & $\begin{array}{l}\text { - Indústria } \\
\text { - Queimadas }\end{array}$ & - Poluição & $\begin{array}{l}\text { - Aumento de } \\
\text { incidência de } \\
\text { doenças } \\
\text { - Perda da qualidade } \\
\text { de vida }\end{array}$ \\
\hline Água & $\begin{array}{l}\text { - Desmatamento } \\
\text { - Resíduos tóxicos } \\
\text { - Terraplanagem } \\
\text { - Impermeabilização } \\
\text { urbana }\end{array}$ & $\begin{array}{l}\text { - Poluição } \\
\text { - Diminuição de } \\
\text { qualidade } \\
\text { quantidade } \\
\text { - Assoreamento }\end{array}$ & $\begin{array}{l}\text { - Incidência de } \\
\text { doenças } \\
\text { - Aumento do custo da } \\
\text { recuperação } \\
\text { - Perda de mananciais }\end{array}$ \\
\hline Vegetação & $\begin{array}{l}\text { - Desmatamento } \\
\text { - Resíduos tóxicos } \\
\text { - Impermeabilização } \\
\text { urbana }\end{array}$ & $\begin{array}{l}\text { - Destruição de } \\
\text { ecossistemas } \\
\text { - Diminuição de } \mathrm{O}_{2}\end{array}$ & $\begin{array}{l}\text { - Perda da fonte de } \\
\text { alimentos } \\
\text { - Aumento da erosão } \\
\text { de solo }\end{array}$ \\
\hline Solo & $\begin{array}{l}\text { - Desmatamento } \\
\text { - Terraplanagem } \\
\text { - Resíduos tóxicos } \\
\text { - Impermeabilização } \\
\text { urbana }\end{array}$ & $\begin{array}{l}\text { - Poluição } \\
\text { - Erosão } \\
\text { - Empobrecimento do } \\
\text { solo } \\
\text { - Compactação de solos } \\
\text { agrícolas } \\
\text { - Rebaixamento do } \\
\text { lençol freático }\end{array}$ & $\begin{array}{l}\text { - Perda do } \\
\text { componente } \\
\text { essencial para as } \\
\text { plantas }\end{array}$ \\
\hline \multicolumn{4}{|c|}{ Interferência Indireta } \\
\hline Clima & $\begin{array}{l}\text { - Desmatamento } \\
\text { - Crescimento urbano } \\
\text { - Poluição do ar }\end{array}$ & $\begin{array}{l}\text { - Modificação do ritmo } \\
\text { climático } \\
\text { - Umidade excessiva } \\
\text { - Temperaturas mais } \\
\text { altas e/ou mais } \\
\text { baixas }\end{array}$ & $\begin{array}{l}\text { - Desconforto térmico } \\
\text { - Aumento de } \\
\text { incidência de } \\
\text { doenças }\end{array}$ \\
\hline Fauna & $\begin{array}{l}\text { - Poluição do ar, água } \\
\text { e solo } \\
\text { - Caçadas } \\
\text { - Desmatamento } \\
\text { - Perda da frente de } \\
\text { alimentos }\end{array}$ & $\begin{array}{l}\text { - Desaparecimento de } \\
\text { espécies } \\
\text { - Aumento de } \\
\text { espécies daninhas } \\
\text { ao homem }\end{array}$ & $\begin{array}{l}\text { - Diminuição da } \\
\text { diversidade biologica } \\
\text { - Aumento de pragas }\end{array}$ \\
\hline Homem & $\begin{array}{l}\text { - Responsável pelas } \\
\text { fontes de impacto }\end{array}$ & $\begin{array}{l}\text { - Perda da qualidade } \\
\text { de vida } \\
\text { - Desequilíbrio } \\
\text { sócio-econômico }\end{array}$ & $\begin{array}{l}\text { - Empobrecimento das } \\
\text { populações } \\
\text { - Favelização } \\
\text { - Subnutrição } \\
\text { - Doenças }\end{array}$ \\
\hline
\end{tabular}


SEQUENCIA DO IMPACTO AMBIENTAL

INTERFERÊNCIA

DIRETA
INTERFERẼNCIA

INDIRETA

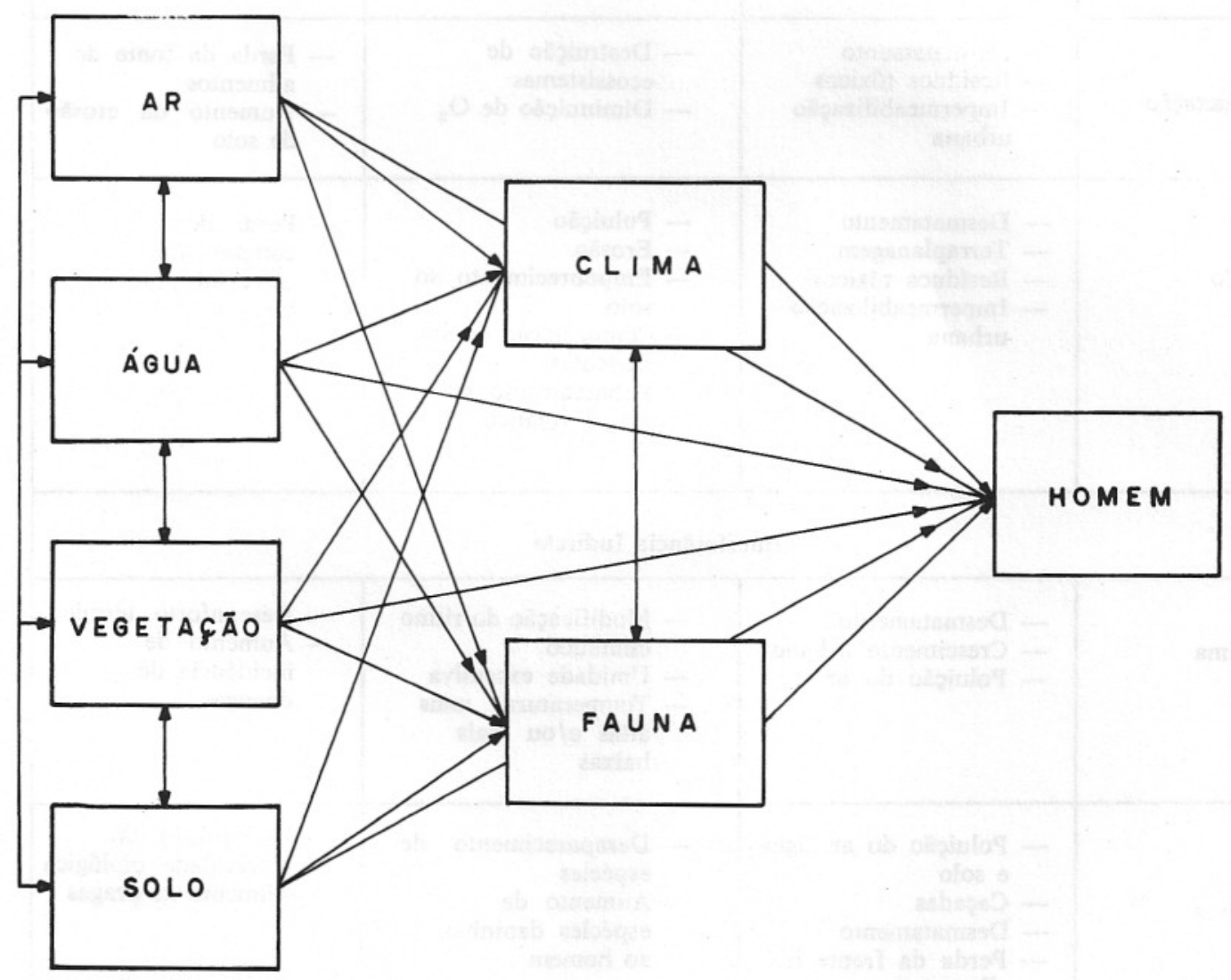

FIGURA I 


\section{PAISAGEM E PERCEPÇÃO AMBIENTAL}

Em BERNALDEZ (1981) "o conceito original de paisagem tem uma conotação de informação, de percepção de uma cena". A percepção da paisagem envolve uma série de operações fisiológica e mentais, que resultam numa forma de comportamento derivado dos estímulos ambientais. $\mathrm{Na}$ atualidade é motivo de amplos estudos, pois o volume de impacto ambiental e as catástrofes naturais são de tal ordem que é necessário saber como o homem se comporta frente a eles e como se adapta. Esses estudos têm amplas conotações sociológicas, antropológicas, psicológicas, etológicas, pois interpretam as várias formas de comportamento humano sendo portanto uma área de convergência multidisciplinar. Tanto os geógrafos quanto outros profissionais envolvidos no planejamento da paisagem tem se interessado pelo estudo da percepção, como um dos meios utilizados na tomada de decisão frente ao conjunto de informações obtidas em determinada região. Torna-se a percepção um instrumento bastante eficiente para promover a participação da comunidade de forma efetiva e objetiva no planejamento da paisagem.

O modelo operacional indicado para estudar a percepção ambiental é o seguinte: sensação, percepção e comportamento ambiental. (fig. 2)

$$
\mathrm{S} \rightarrow \mathrm{P} \rightarrow \mathrm{C}
$$

A maior parte dos componentes da paisagem podem ser observados através dos sentidos e dependem dos estímulos sensoriais.

SENTIDO
$\begin{array}{ll}\text { - ESTIMULO } \\ \text { visão } & - \text { luz, cor, forma } \\ \text { audição } & - \text { som } \\ \text { tato } & - \text { forma, textura, } \\ & \text { extensão, } \\ & \text { temperatura } \\ \text { olfato } & - \text { cheiro } \\ \text { paladar } & - \text { gosto }\end{array}$

$\mathrm{O}$ conjunto de informações sensoriais promovem a percepção que já implica no processo de identificação. As informações de cor, formas, tamanho, luz, levam à identifi- cação dos fatos visuais que são na paisagem, vegetação, relevo, afloramento rochoso, água superficial e formas de uso da terra. Com a audição tem-se a identificação da voz dos animais, do ruído, dos fenômenos naturais e culturais (vento, trovão, ruído de máquinas); com o tato tem-se a percepção de forma (arredondada, plana, etc.), dimensão, textura, identificação de frio e calor; e assim por diante em relação aos outros sentidos.

O comportamento ambiental resulta da ação do conjunto de percepções, sendo assim a maneira como o ser humano interpreta as informações sensoriais e perceptivas. A finalidade desse processo é criar meios para se adaptar à paisagem, ao meio ambiente. $\mathrm{O}$ homem do Nordeste quando ouve o canto de determinado pássaro, percebe qual o fenômeno natural que poderá acontecer, se irá chover ou continuar a estiagem. $\mathrm{O}$ ser humano vivendo em comunidades mais próximas da natureza tem um sentido de percepção mais acurado em função da paisagem, se comparado ao que vive nas grandes cidades, pois possue uma personalidade ambiental mais definida.

A percepção e comportamento ambiental são responsáveis pela formação da cultura. Quando um agrupamento humano vive um determinado local por longo tempo, sua tendência é de aprender a se adaptar às condições existentes nesse local. Todas as atividades passam a ser condicionadas por estas atividades, assim moradia, vestuário, hábitos alimentares são regulados pelo potencial do meio existente, bem como das informações sensoriais e perspectivas desse local.

Um determinado grupo quando migra, adquire uma certa tendência de perda da percepção ambiental. Em contacto com novos meios e novos estímulos sensoriais torna-se difícil a adaptação à nova situação que se vê agravada pela pressão sócio-econômica desfavorável. Os migrantes do norte do país que se dirigem às grandes cidades do sul, constroem suas casas nas encostas instáveis ou em áreas insalubres de alagados. São situações muito mais diversas daquelas de onde vieram. Estão surgindo numerosas favelas nas encostas da Serra do Mar e nos mangues da Baixada Santista.

Os antropólogos chamam o processo citado acima de aculturação. A perda mais grave relacionada a este processo é a da 
PERCEPÇÃO AMBIENTAL

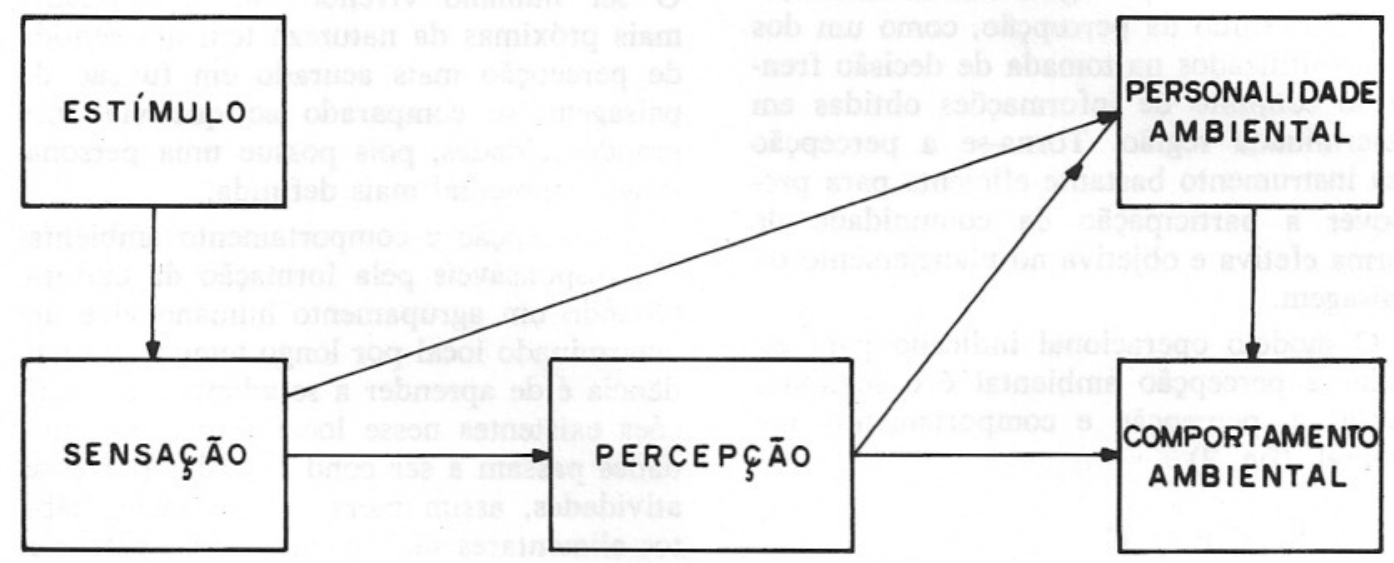

FIGURA 2 
noção de perigo que é um dos mecanismos básicos do instinto de sobrevivência. Aconteceu um fato dramático em março de 1984, foi o incêndio da Vila Socó em Cubatão. Um grupo de migrantes construíram suas moradias em cima de um oleoduto da Petrobrás, e com $\mathrm{o}$ incêndio deste ocorrem centenas de mortes e perdas materiais de grande monta.

É necessário que se tente estabilizar os agrupamentos humanos para haver uma convivência equilibrada com a natureza. Somente assim será possível perceber e compreender seus mecanismos.

\section{TENTATIVA DE REGIONALIZAÇÃつ PAISAGISTICA DO ESTADO DE SÃO PAULO}

A tentativa de regionalização da paisagem baseia-se em OLIVEIRA apud GEISER et alii (1978) quando foram descritas as macrounidades paisagísticas do Estado de São Paulo com algumas áreas de impacto ambiental intenso.

O presente trabalho retoma os conceitos do anterior e os amplia, mostrando mais detalhes quanto ao arranjo do conjunto de fatores ambientais que determinam as unidades paisagísticas. (fig. 3)

Macrounidade paisagística I - Representa basicamente uma relação entre embasamento geológico e seu reflexo geomorfológico. Caracteriza-se por conter uma grande diversidade de rochas duras e resistentes aliadas a uma topografia bastante acidentada. É um ambiente de grande vulnerabilidade com baixa capacidade de carga. A grande diversidade rochas, topografia, solos aliada à ação contínua de massas de ar carregadas de umidade promoveu uma grande diversidade de ecossistemas e portanto de formas de vida.

Esta região possue povoamento mais antigo e a maior concentração demográfica do país. Em decorrência disto o volume de atividades humanas provoca uma considerável quantidade de impacto nesta área.

IA - É uma submacrounidade paisagística. Pode ser considerada a área representativa da macrounidade I, embora apresente aspectos diversificados quantos fatos paisagísticos.

IB - Esta submacrounidade representa um fator cultural marcante, o urbano. Tra- ta-se da região metropolitana de São Paulo. Os impactos ambientais na grande cidade são intensos e extensos. Surgem no centro com o adensamento urbana indo à periferia com o povoamento desordenado.

IC - Trata-se da Bacia do Rio Paraíba. $\mathrm{O}$ fato marcante nesta região é a linearidade da urbanização São Paulo-Rio com seus problemas peculiares. Nas áreas mais acidentadas a erosão é intensa acarretando um grande assoreamento na rede hidrográfica.

ID - São as áreas mais acidentadas do Estado de São Paulo. Na direção NNE surge a Serra da Mantiqueira e a SSE a Serra do Mar. Devido ao fato de serem áreas muito acidentadas não há povoamento pleno, mas esparso. Conservam assim, grande parte das paisagens naturais, intocadas e de grandes belezas naturais.

$\mathrm{Na}$ Serra do Mar próximo à Baixada Santista existe o problema da poluição intensa que está destruindo os ecossistemas naturais. Em Cubatão as favelas sobem as encostas da serra e estão em situação de grande perigo em face da instabilidade desses sítios.

IE - A região litorânea apresenta planícies costeiras em contato com as escarpas da Serra do Mar. Possue grandes belezas naturais que atraem os turistas, motivando a especulação imobiliária desenfreada que desestrutura o espaço.

Apresenta como nas outras macrounidades grande volume de impacto.

Macrounidade paisagística II - Representa quase 2/3 do Estado de São Paulo, sendo como na outra macrounidade uma reação entre rocha e relevo. Caracteriza-se por conter rochas sedimentares e um relevo menos acentuado onde as formas tabulares são uma constante. A exceção é a região das cuestas basálticas onde surgem rochas mais resistentes, fruto de derramamentos basálticos. O relevo aí, torna-se mais aćidentado com escarpas íngremes e topos planos.

A diversidade biológica na macrounidade paisagística II é menor se comparada com a I, existem menos unidades de ecossistemas naturais. A presença do homem é intensa e a fisionomia da paisagem é caracterizada pelos fatores culturais agrícolas e urbanos.

IIA - Submacrounidade paisagística Trata-se do Planalto Ocidental; região ca- 


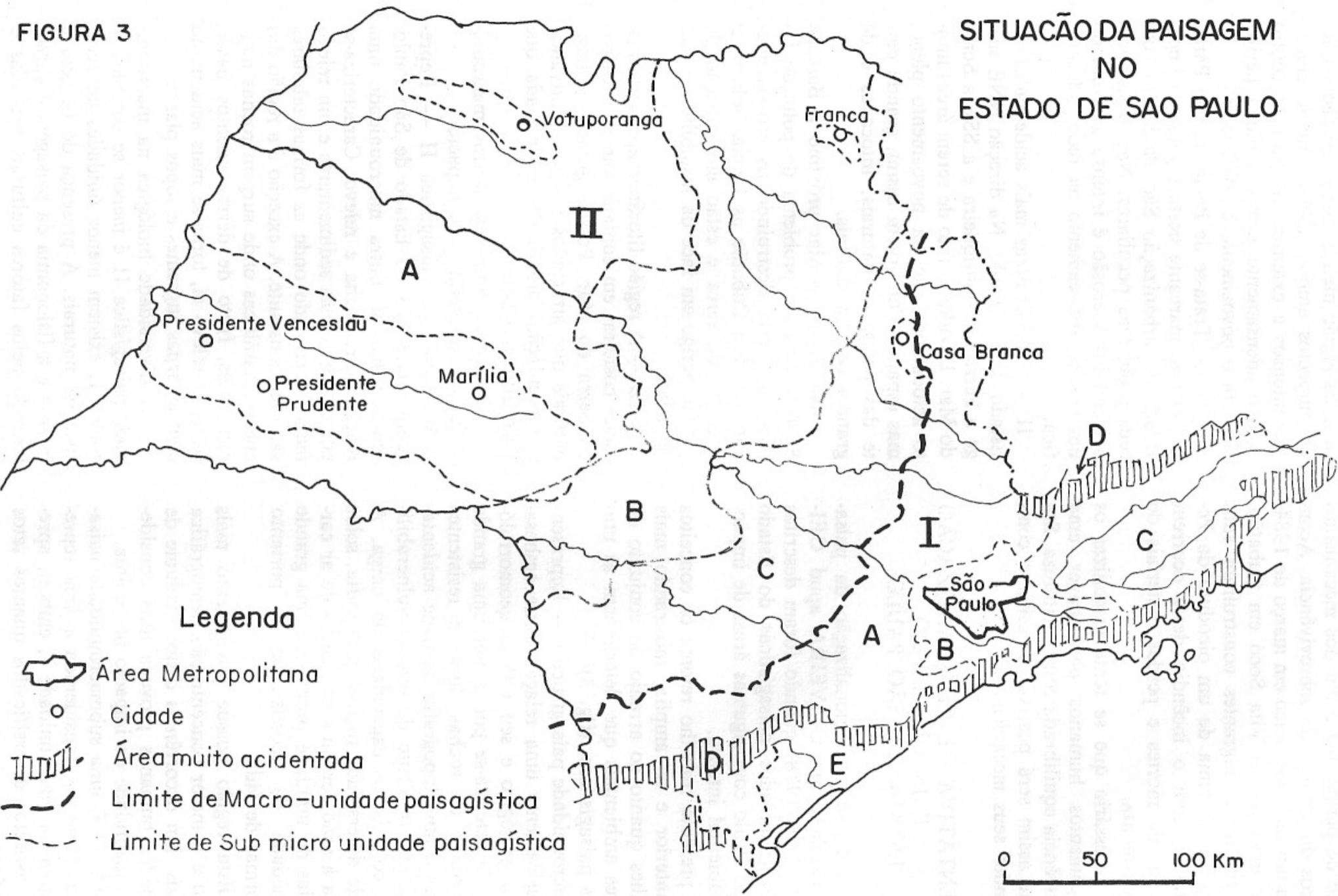


racterizada por umà topografia plana e tabuliforme fruto da decomposição de rochas sedimentares do grupo Bauru, com algum afloramento do basalto onde a topografia se torna mais movimentada. Os solos são relativamente ricos e a ocupação da agricultura é intensa. Mais ao sul do Planalto Ocidental, numa ampla faixa que vai de Presidente Prudente e Marília, surge uma área mais vulnerável que em decorrência da ocupação humana, apresenta um amplo processo de erosão e voçorocamento. O mesmo fato aparece ao norte da região de Votuporanga.

IIB - Na região das cuestas basálticas encontra-se a terra rocha, o solo mais fértil do Estado de São Paulo. A urbanização nessa área tem avançado sobre esses solos anulando-os com a impermeabilização decorrente das construções.

IIIC - A submacrounidade paisagística a seguir é bastante complexa do ponto de vista do embasamento geológico pois aí aparecem inúmeras formações. No entanto ele se caracteriza por ser uma área rebaixada em relação à macrounidade paisagística I e se contrapõe ao front das cuestas basálticas. Essa região rebaixada recebeu o nome de Depressão Periférica. Apresenta solos bem mais pobres que as regiões IIA e IIB, o impacto ambiental é mais elevado havendo inclusive a formação de uma área metropolitana na região de Campinas e arredores. A vulnerabilidade ambiental é variável. Em algumas áreas demarcadas na figura 3 ocorre erosão intensa e voçorocamento.

\section{CONSIDERAÇÕES FINAIS}

Os temas que foram apresentados e discutidos nesse trabalho evidenciam mostrar o amplo espectro do estudo da paisagem como subsídio do Planejamento Ambiental. No momento presente, em face do descaso com que o assunto "ambiente" vem sendo tratado as medidas para a recuperação ambiental são setorizadas e emergenciais. Enquanto isso os problemas se avolumam. Os técnicos interessados em propor soluções para os problemas do meio ambiente e da paisagem, terão uma área de atuação bastante espinhosa e complexa como cenário de intervenção.

Urge que os profissionais em planejamento ambiental apliquem medidas que deixem de ser setorizadas e passem a ser globais. A natureza é um conceito global. Somente através das medidas preconizadas acima será possível conviver com a natureza em toda sua magnitude.

\section{REFERENCIAS BIBLIOGRÁFICAS}

ALMEIDA, F.F.M. de - 1974 - Fundamentos zeológicos do relevo paulista. São Paulo, Universidade, Instituto do Geografia. 110p. (Série Teses e monografias, 14)

BERNALDEZ, F.G. - 1981 - Ecologia y paisáje. Madrid, H. Blume Ediciones. 251p.

BERTRAND, G. - 1971 - Paisagem e geografia física global: esboço metodológico. São Paulo, Universidade, Instituto de Geografia, 27p. (Caderno de ciências da terra, 13)

- 1972 - La science du paysaje, une science diagonale. Révue Géographique des Pyrennées et du Sud-Oueste, Toulouse, 43(2): 127-132.

CHIOSSI, N.J. - 1983 - Impactos ambientais e sociais no uso e ocupação do solo. São Paulo, CETESB, Secretaria de Obras do Meio Ambiente. $8 \mathrm{fls}$. (Trabalho apresentado no $27 .^{\circ}$ Congresso Estadual de Municípios)

DAJOZ, R. - 1973 - Ecologia geral; tradução de Francisco M. Guimarães. 2. ${ }^{a}$ ed. Petrópolis, Vozes, São Paulo, Editora da USP. 480p
DEMEK, J. - 1978 - The landscape as a geosystem. Geoforum, Oxford, 9(1):29-34.

GEISER, R.R. et alii - 1978 - A necessidade de uma legislação para promoção e defesa da paisagem. Boletim informativo da Sociedade Brasileira de Ciência do Solo. Campinas, SP, 3(3):32-36.

HUBSCHMAN, J. - 1972 - Sols et paysages: quelques problèmes d'ecólogie du sol. Révue Géoghaphique des Pyrenées et du Sud-Ouest. Toulouse, 43(2):147-156.

KLINK, H.J. - 1974 - Geocology and natural regionalisation: bases for environmental research. Applied Sciences and Development, Tübingen, 4:48-74.

MANSHARD, W. - 1973 - Man and the biosphere. Applied Sciences and Development, Tübingen, 1:60-65.

MONTEIRO, C.A. de Figueiredo - 1978 - Derivações antropogênicas dos geossistemas terrestres no Brasil e alterações climáticas: perspectivas urbanas e agrárias ao problema da elaboração de modelos de avaliação. In: SIM- 
Rev. IG, São Paulo, 4(1/2): 67-78, jan./dez. 1983

POSIO SOBRE A COMUNIDADE VEGETAL COMO UNIDADE BIOLOGICA, TURÍSTICA E ECONÔMICA, São Paulo, 1978. Anais... São Paulo, Secretaria da Cultura, Ciência e Tecnologia, Academia de Ciências do Estado de São Paulo. p. 43-75. (Publicação ACIESP, 15)

OLIVEIRA, M.C. et alii - 1976 - A natureza e o homem no Estado de São Paulo: um panorama. São Paulo, Sociedade Brasileira de Paisagismo. 49fls.

\section{to de meio ambiente. Revista do Instituto Geológico, São Paulo, 3(2):53-60, jul./dez.}

SEIBERT, P. - 1974 - Seminário; manejo da paisagem e mapeamento da vegetação do Parque Estadual de Campos do Jordão; tradução de Walter Emmerich. São Paulo, Instituto Florestal. 198p. (Publicação IF, 5)
SCHREIBER, K.F. - 1977 - Landscape planning and protection of the environment. Applied Sciences and Development, Tübingen, 9:128139.

SOTCHAVA, V.B. - 1977 - O estudo de geossistemas. São Paulo, Universidade, Instituto de Geografia. 52p. (Métodos em questão, 16)

- 1978 - Por uma teoria de classificação de geossistemas de vida terrestre. São Paulo, Universidade, Instituto de Geografia. 24p. (Biogeografia, 14)

VINK, A.P.A. - 1982 - Landscape ecological mapping. ITC Journal, Enschede, (3):338-343. [Special Verstappen issue]

ZONNEVELD, I.S. - 1982 - The ecosciences in resource and environmental surveys. ITC Journal, Enschede, (1):17-18. [Special 30th anniversary issue] 